\title{
Does People's Wellbeing Get Impacted by COVID-19 Pandemic Measure in Indonesia?
}

\author{
DAVID TJAHJANA ${ }^{1}$, DIENA DWIDIENAWATI ${ }^{2}$, ADLER HAYMANS MANURUNG ${ }^{3}$, DYAH \\ GANDASARI $^{4}$ \\ ${ }^{1}$ Department of Information System. UNIVERSITAS MULTIMEDIA NUSANTARA, INDONESIA. \\ E-mail: davidtjdd@gmail.com \\ 2Department of Business School, BINA NUSANTARA UNIVERSITY, INDONESIA. diena.tjiptadi@gmail.com \\ ${ }^{3}$ Department of DRM Business School, BINA NUSANTARA UNIVERSITY, INDONESIA. adler.manurung@gmail.com \\ ${ }^{4}$ Bogor Agriculture Development Polytechnic (POLBANGTAN Bogor), Ministry of Agriculture, INDONESIA. \\ dyahgandasari@yahoo.com
}

\begin{abstract}
The impact of COVID-19 pandemic is not only to human health but also to other aspects of human life. The most common action taken by the government in order to prevent the spread of the infection is mobility restriction. The implication of this mobility restriction is limitation of social activities which can be done. Mobility restriction was implemented in Jakarta and its surrounding cities and impacted more than 20 million people. Is this mobility restriction impacting people's wellbeing? The objective of this study is to see whether there is an impact on wellbeing- in terms of happiness and life satisfaction in Indonesia due to mobility restriction. A survey was conducted in April 2020. Happiness and satisfaction with life were measured by using the Subjective Happiness Scale (SHS) and Satisfaction with Life Scale (SWL). The reliability and validity of measures were analyzed with SPSS, and the differences between groups were analyzed with Two-Sample T-Test. The study finds that the respondents' happiness level was only slightly happy, and the level of satisfaction was only slightly satisfied. The respondents claimed that their happiness was deteriorated during mobility restriction $(41 \%)$. Thirty-four percent felt their satisfaction was deteriorated. Student group is shown as the most impacted group in its scale of wellbeing. The finding of this study can give insight for policymakers in implementing restrictive measures. The result of this study gives an insight into which groups to be prioritized for support or helped to cope with the restriction.
\end{abstract}

Keywords: happiness, mobility restriction, satisfaction, wellbeing

JEL Classification: J 


\section{Introduction}

Starting at the end of 2019, Coronavirus (COVID-19) has spread rapidly worldwide and become a pandemic. This large-scale pandemic outbreak is not only affecting human's health, but it is also affecting other aspects of human life(Huang, Liu, Tlili, Yang, \& Wang, 2020). It is affecting a day-to-day life significantly.

The recommendation for countries with widespread transmission is to do mobility restriction, limit social interaction, and prohibit any crowd gathering. People have to be encouraged to stay home and if possible, to work from home (Fisher \& Wilder-Smith, 2020). In a short span, a novel coronavirus has captured global consciousness by significantly affecting the day-to-day life of humans (Peeri et al., 2020).

On March 2nd, 2020, the government announced the first 2 cases of COVID-19 in Indonesia. Afterward, the number of cases has become escalating. Social distancing measure was implemented soon afterward. Schools were shifted to online method. Government institutions and private sectors implemented work from home and alternate working arrangements. Yet, some businesses still worked as usual with workspace arrangement.

In Jakarta and its surrounding cities, more than 20 million people get affected by mobility restriction. It is important to understand the implication of mobility restriction not only on the prevalence of the disease but also its implication on health and wellbeing of the people. This study aims to provide empirical data on wellbeing in terms of happiness and life satisfaction in Indonesia one month into the COVID-19 outbreak. Currently, there are limited studies providing field evidences on the wellbeing of people who do not have a viral infection but confined in varying degrees over a month.

\section{Literature Review}

The recommendation for countries with widespread transmission is to do mobility restriction, limit social interaction, and prohibit any crowd gathering. People have to be encouraged to stay home and if possible, to work from home (Fisher \& Wilder-Smith, 2020). In a short span, a novel corona virus has captured global consciousness by significantly affecting the day-to-day life of humans(Peeri et al., 2020). When the outbreak becomes progressing, one of the many changes in the request is to social distancing, working from home, and distance learning method for students.

The mobility restriction might implicate people's wellbeing. Studies on wellbeing have expanded dramatically (VanderWeele et al., 2020). Various studies reveal the predictors of wellbeing as well as the impact on wellbeing. Extrinsic and intrinsic goals have been known to influence wellbeing. $A$ research also reveals that if people can fulfill the four psychological needs: security and safety; competence and efficacy; connection to others; and autonomy and authenticity, their wellbeing will be enhanced (Linley \& Joseph, 2004). (Michalos, 2008) states that people's living conditions affect how they feel good about themselves.

Physical activities are also known to have an impact on people's wellbeing. The study from (MacKerron \& Mourato, 2013) shows that being outdoor makes people feel happier. (García-Hermoso, Hormazábal-Aguayo, Fernández-Vergara, Olivares, \& Oriol-Granado, 2020) claimed that children with less physical activities have lower life satisfaction. (Tamminen et al., 2020) states that physical inactivity was linked to a lower level of positive mental health. Studies also prove that uncertainty, cultural context, and some major events of life such as separation, illness, and monetary losses have an impact on people's wellbeing.

The outcomes of wellbeing include reduced risk of both physical and mental illnesses, better social functioning, higher academic achievement, and reduced mortality (Tamminen et al., 2020). (Lawrence, Rogers, \& Wadsworth, 2015) shows that the risk of death of not happy people is $14 \%$ higher compared to very happy people. Wellbeing is also known to have an association to lower count of white blood cells, independence of mental ill-health (Fancourt \& Steptoe, 2020). 
Human wellbeing is one of the focuses of positive psychology. Positive psychology has a direct focus on promoting what is good in life (Tal \& Kerret, 2020) and the aspect of optimal human functioning (Linley \& Joseph, 2004). It is defined as the science of human functioning (Tal \& Kerret, 2020). The interest of what is good about life and optimal human functioning has gone way back to Aristotle with eudaimonia or general wellbeing, in his phrase, "living well and doing well" (Michalos, 2008).

Wellbeing is known to comprise two main factors: hedonic perspective and eudemonic perspective or feeling good perspective and well-functioning perspective (Tamminen et al., 2020). In other words, it can be said that there were two aspects of wellbeing, which are a cognitive aspect and a subjective aspect. In this study, the focus will be on the subjective aspect of wellbeing. The subjective aspect of wellbeing is measured with happiness and satisfaction in life (Mathews, 2012; VanderWeele et al., 2020).

Happiness is a narrower concept of subjective wellbeing (SWB), so happiness is only a part of a person's overall wellbeings (Conceição \& Bandura, 2008; Jongbloed \& Andres, 2015). Happiness is "'happiness as an Aristotelian eudaimonia or general wellbeing involving, in his phrase, "living well and doing well" by enjoying goods of the mind (e.g., wisdom, moral virtue, and pleasure), goods of the body (e.g., physical beauty, health, and pleasure again), and external goods (e.g., wealth and adequate material resources, good parents and families, good friends, peace and security within and between communities, and well-governed communities"(Michalos, 2008). Happiness is not constant over time. It is influenced by many valued domains of life (Jongbloed \& Andres, 2015). Happiness is an important indicator of human wellbeing (Conceição \& Bandura, 2008).

Kahneman and Krueger define life satisfaction "...is a global retrospective judgment, which, in most cases, is constructed only when asked and is determined in part by the respondent's current mood and memory and by the immediate context" (Mathews, 2012). The subjective satisfaction of life measurement is to assess people's life satisfaction as a whole. Even though the measure does not include assessment of satisfaction with life domains such as health or finance, subjective satisfaction with life measurement allows the integration and weight of these domains in whatever way people choose (Diener, Emmons, Larsen, \& Griffin, 1985).

\section{Methodology}

This study aims to provide empirical data on wellbeing in terms of happiness and life satisfaction in Indonesia one month into the COVID-19 outbreak. A quantitative study was conducted to see the people's wellbeing during the mobility restriction. This study was using structured questionnaires as the instruments. Questionnaires were distributed online. Due to resource and time limitations, this study used a convenience sampling method. Questionnaires were sent to 455 people in big cities in Indonesia. The returned questionnaires were screened based on completeness. If there were more than 2 missing data for each item (Happiness and Satisfaction), the questionnaires were omitted.

\section{Measures}

Wellbeing was measured by happiness and satisfaction with life. The measurement of happiness used the Subjective Happiness Scale (SHS) (Orth et al., 1999). Respondents were asked to self-rate from 1 (not at all) to 7 (a great deal) to four statements. These statements include "In general, I consider myself", "Compared to most of my peers, I consider myself"; "Some people are generally very happy. They enjoy life regardless of what is going on, getting the most out of everything. To what extent does this characterization describe you?"; "Some people are generally not very happy. Although they are not depressed, they never seem as happy as they might be. To what extent does this characterization describe you?".

The satisfaction measure was using the Satisfaction with Life Scale (SWL). This scale was developed by (Diener et al., 1985). There were five statements in which respondents needed to self-rate from scale 1 (strongly disagree) to 7 (strongly agree). The five statements include "In most ways, my life is 
close to my ideal"; "The conditions of my life are excellent"; "I am satisfied with my life"; "So far, I have gotten the important things I want in life" and "If I could live my life over, I would change almost nothing".

Respondents were also asked to rate their level of happiness and satisfaction compared to normal conditions. Additional demographic information such as gender, educational background, and current status was also asked.

\section{Data Analysis}

The reliability and validity of happiness and satisfaction measured were analyzed by SPSS. The assessment of happiness and satisfaction for each group was conducted. The different values between each group and the total value were calculated with Two-Sample T-Test.

\section{Result}

From 455 questionnaires, there were 268 questionnaires returned. Due to missing data, only 244 questionnaires were eligible to be further analyzed. From total respondents, $49 \%$ was male, $50 \%$ was female, and $1 \%$ was preferred not to answer (Figure 1 ).

Figure 1. Gender Profiles

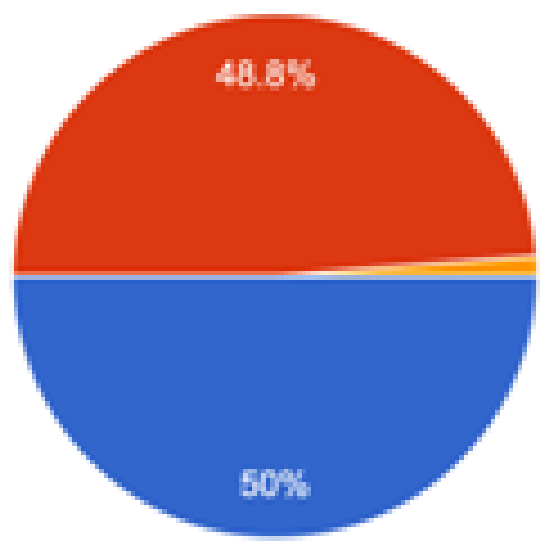

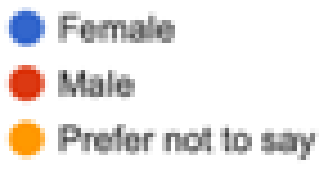

From total respondents, $48 \%$ was WFH now, $27 \%$ was online students, $11 \%$ was alternate working, $6 \%$ was working as usual, and $8 \%$ was others (retirements, housewives, and not working) (Figure 2). Educational background profiles from respondents showed that $48 \%$ of them were with bachelor's degree, $33 \%$ was active students in a university, and $16 \%$ was with master's degree (Figure 3 ).

Figure 2. Current Status

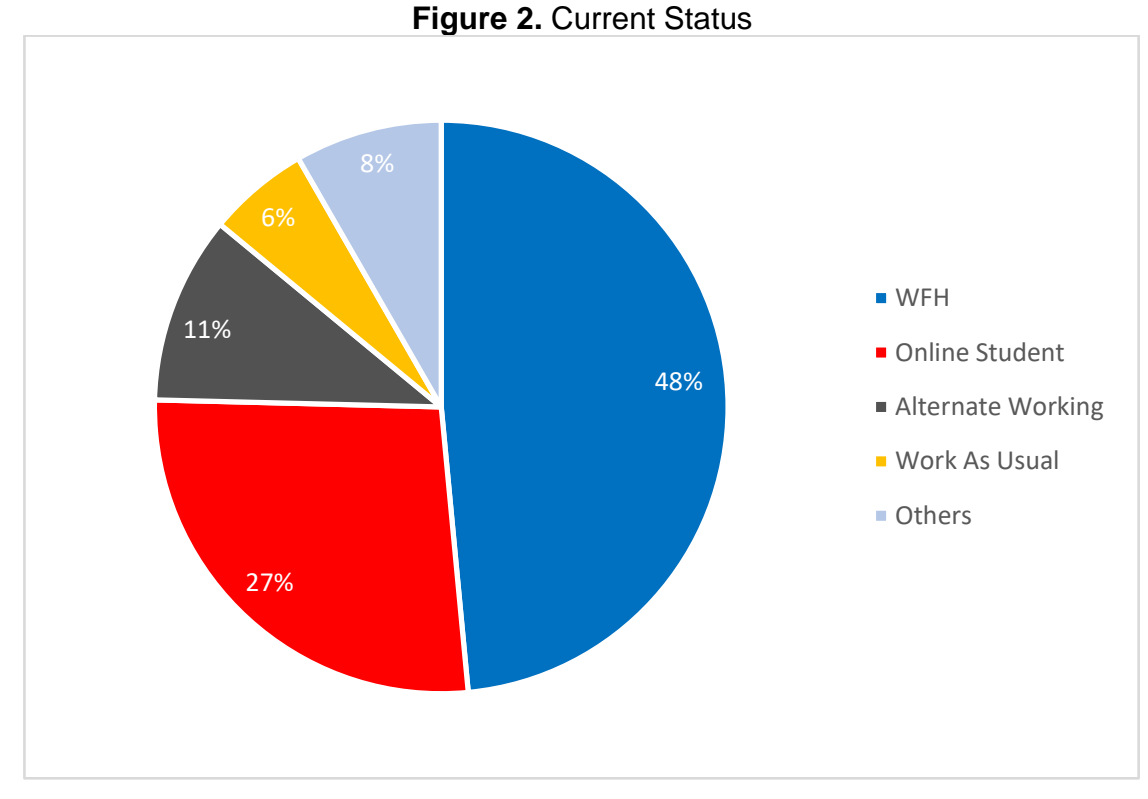


Figure 3. Educational Profiles

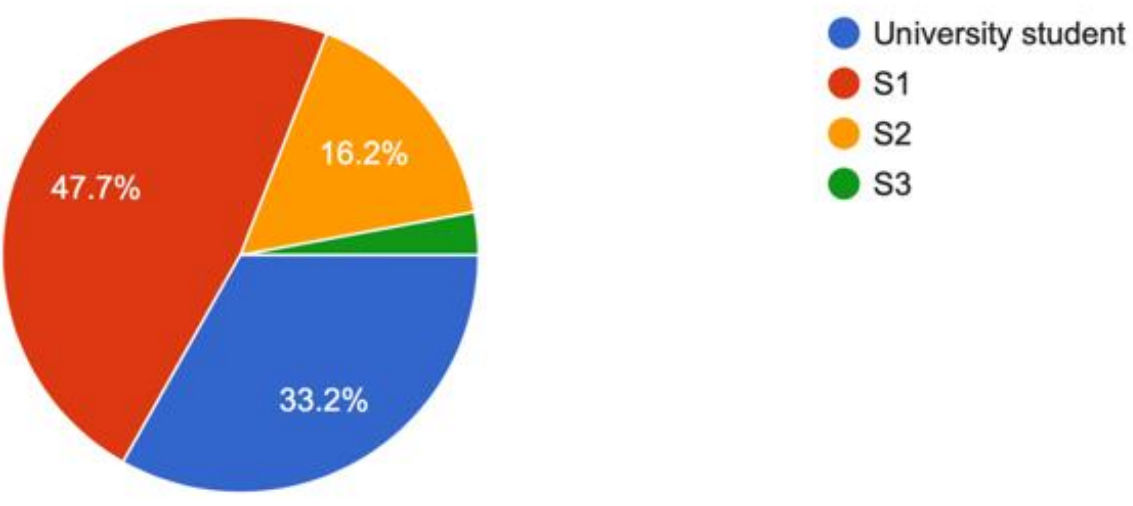

The respondents were from all over Indonesia such as Sumatera, Kalimantan, Sulawesi, Central Java, West Java, East Java, and Jakarta. However, most questionnaires returned (82\%) were from Jakarta and its surrounding cities such as Bogor, Bekasi, Tangerang, Depok, while only eighteen percent came from other parts of Indonesia (Figure 4).

Figure 4. Location Profiles

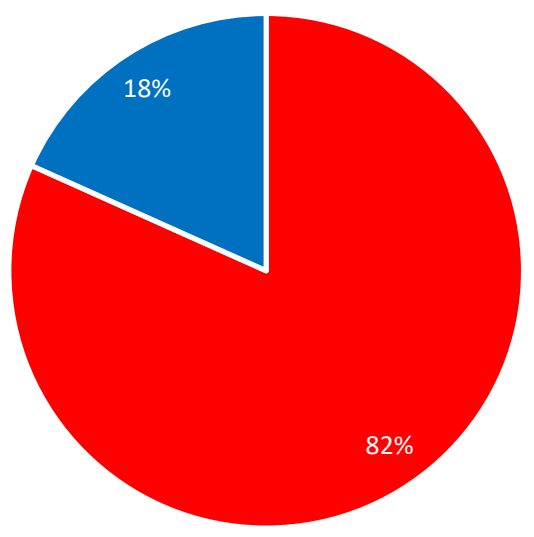

- Jabodetabek

- Others

The SPSS analysis showed that the measurement of happiness was valid and reliable. The Pearson Correlation for 4 indicators of happiness were above 0.304 . Therefore, it can be concluded that the measurements of satisfaction were valid. Cronbach's alpha value for all indicators of satisfaction was $<0.5$. Therefore, the happiness measurements had internal consistency (Table 1). The SPSS analysis showed that the measurement of satisfaction was valid and reliable. The Pearson Correlation for 5 indicators was above 0.304 . Therefore, it can be concluded that the measurements of satisfaction were valid. Cronbach's alpha value for all indicators of satisfaction was $<0.5$. Therefore, the satisfaction measurements had internal consistency (Table 2).

Respondents scored their happiness with an average score of 5.2 from score range 1-7, or respondents agreed that they were slightly happy. Each group's happiness score was then compared with the total group score. Comparison between each group to total group score showed that only group of online students found to have happiness score less than the total respondent score (mean value 4.7 online students vs 5.2 total respondents). When asked "how is their happiness status compared to normal condition?", forty-one percent of respondents evaluated that their happiness was somehow deteriorated (from slightly deteriorated to very much deteriorated) (Figures 5 and 6). 
Table 1. Pearson Correlation of Happiness Measurement Correlations

\begin{tabular}{|c|c|c|c|c|c|c|}
\hline & & SHS01 & SHS02 & SHSO3 & SHSO4 & TOTAL \\
\hline \multirow[t]{3}{*}{ SHS01 } & Pearson Correlation & 1 & $.706^{\star *}$ & $.457^{\star *}$ & $.263^{* *}$ & $.751^{\star \star}$ \\
\hline & Sig. (2-tailed) & & .000 & .000 & .000 & .000 \\
\hline & $\mathrm{N}$ & 244 & 244 & 244 & 243 & 244 \\
\hline \multirow[t]{3}{*}{ SHS02 } & Pearson Correlation & $.706^{\star *}$ & 1 & $.592^{\star *}$ & $.404^{\star \star}$ & $.843^{* *}$ \\
\hline & Sig. (2-tailed) & .000 & & .000 & .000 & .000 \\
\hline & $\mathrm{N}$ & 244 & 244 & 244 & 243 & 244 \\
\hline \multirow[t]{3}{*}{ SHSO3 } & Pearson Correlation & $.457^{\star \star}$ & $.592^{\star \star}$ & 1 & $.404^{\star *}$ & $.785^{* *}$ \\
\hline & Sig. (2-tailed) & .000 & .000 & & .000 & .000 \\
\hline & $\mathrm{N}$ & 244 & 244 & 244 & 243 & 244 \\
\hline \multirow[t]{3}{*}{ SHSO4 } & Pearson Correlation & $.263^{* *}$ & $.404^{\star *}$ & $.404^{* \star}$ & 1 & $.718^{* *}$ \\
\hline & Sig. (2-tailed) & .000 & .000 & .000 & & .000 \\
\hline & $\mathrm{N}$ & 243 & 243 & 243 & 243 & 243 \\
\hline \multirow[t]{3}{*}{ TOTAL } & Pearson Correlation & $.751^{\star *}$ & $.843^{* *}$ & $.785^{* *}$ & $.718^{* *}$ & 1 \\
\hline & Sig. (2-tailed) & .000 & .000 & .000 & .000 & \\
\hline & $\mathrm{N}$ & 244 & 244 & 244 & 243 & 244 \\
\hline
\end{tabular}

**. Correlation is significant at the 0.01 level (2-tailed).

For satisfaction score, the average score of respondents' satisfaction was 4.7 from score range 1-7, or respondents agreed that they were slightly satisfied. From the comparison between each group to total group score, only group of online students found to have satisfaction score lower than the total group satisfaction score (mean value 4.3 online students vs 4.7 total respondents). When asked "how is their satisfaction with life status compared to normal condition?", thirty-four percent of respondents evaluated that their satisfaction was somehow deteriorated (from slightly deteriorated to very much deteriorated) (Figure 7 \& 8).

Figure 5. Happiness Scores

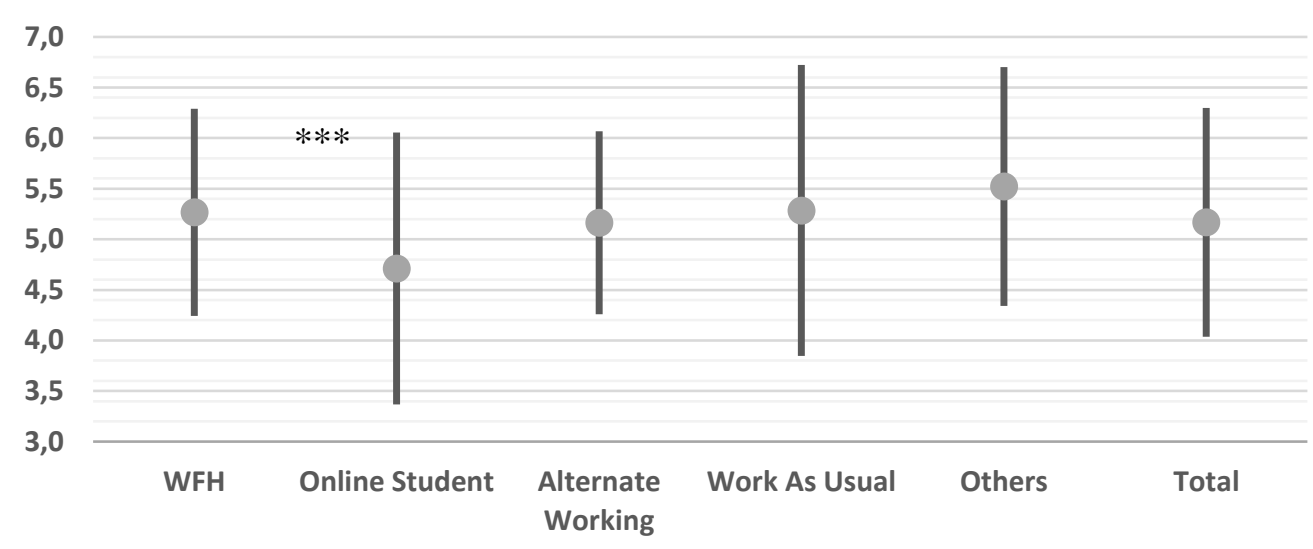

${ }^{* * *}$ p-value $<0.05$

Students and people who work as usual rated themselves 3.8 and 3.9 (slightly deteriorated-no change) respectively for happiness. The values were the lowest compared to other groups. However, there was no significant difference compared to overall rates. Students and people who work as usual 
also rated themselves the lowest for satisfaction. However, there was also no significant difference compared to overall rates.

Table 2. Pearson Correlation of Satisfaction Measurement

\begin{tabular}{|c|c|c|c|c|c|c|c|}
\hline \multicolumn{8}{|c|}{ Correlations } \\
\hline & & SWL01 & SWL02 & SWL03 & SWL04 & SWL05 & TOTAL \\
\hline \multirow[t]{3}{*}{ SWL01 } & Pearson Correlation & 1 & $.665^{* *}$ & $.617^{\star *}$ & $.514^{* *}$ & $.325^{\star *}$ & $.802^{* *}$ \\
\hline & Sig. (2-tailed) & & .000 & .000 & .000 & .000 & .000 \\
\hline & $\mathrm{N}$ & 244 & 244 & 243 & 244 & 244 & 244 \\
\hline \multirow[t]{3}{*}{ SWL02 } & Pearson Correlation & $.665^{\star *}$ & 1 & $.660^{* *}$ & $.589^{* *}$ & $.265^{* *}$ & $.811^{\star *}$ \\
\hline & Sig. (2-tailed) & .000 & & .000 & .000 & .000 & .000 \\
\hline & $\mathrm{N}$ & 244 & 244 & 243 & 244 & 244 & 244 \\
\hline \multirow[t]{3}{*}{ SWL03 } & Pearson Correlation & $.617^{\star *}$ & $.660^{* *}$ & 1 & $.530^{* *}$ & $.345^{* *}$ & $.819^{* *}$ \\
\hline & Sig. (2-tailed) & .000 & .000 & & .000 & .000 & .000 \\
\hline & $\mathrm{N}$ & 243 & 243 & 243 & 243 & 243 & 243 \\
\hline \multirow[t]{3}{*}{ SWL04 } & Pearson Correlation & $.514^{* *}$ & $.589^{* *}$ & $.530^{\star *}$ & 1 & $.332^{* *}$ & $.758^{* *}$ \\
\hline & Sig. (2-tailed) & .000 & .000 & .000 & & .000 & .000 \\
\hline & $\mathrm{N}$ & 244 & 244 & 243 & 244 & 244 & 244 \\
\hline \multirow[t]{3}{*}{ SWL05 } & Pearson Correlation & $.325^{* *}$ & $.265^{* *}$ & $.345^{* *}$ & $.332^{* *}$ & 1 & $.633^{* *}$ \\
\hline & Sig. (2-tailed) & .000 & .000 & .000 & .000 & & .000 \\
\hline & $\mathrm{N}$ & 244 & 244 & 243 & 244 & 244 & 244 \\
\hline \multirow[t]{3}{*}{ TOTAL } & Pearson Correlation & $.802^{* *}$ & $.811^{\star \star}$ & $.819^{\star \star}$ & $.758^{\star \star}$ & $.633^{\star \star}$ & 1 \\
\hline & Sig. (2-tailed) & .000 & .000 & .000 & .000 & .000 & \\
\hline & $\mathrm{N}$ & 244 & 244 & 243 & 244 & 244 & 244 \\
\hline
\end{tabular}

${ }^{* *}$. Correlation is significant at the 0.01 level (2-tailed).

Figure 6. Deterioration of Happiness

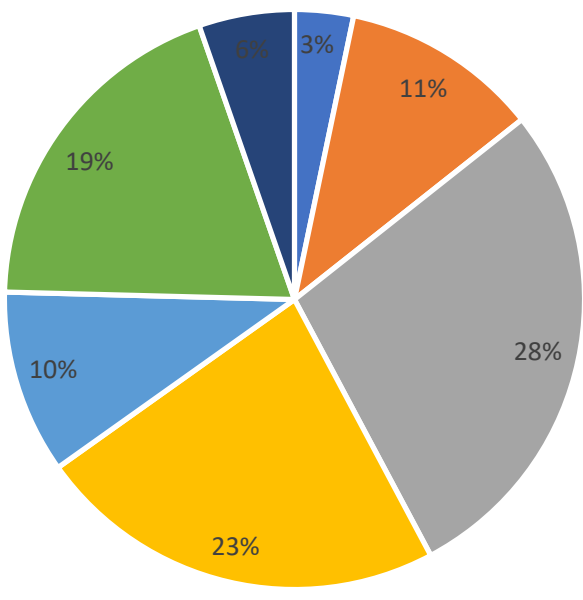

- Very deteriorated

- Deteriorated

- Slightly deteriorated

- No Change

- Slightly better

- Better

- Much better 
Figure 7. Satisfaction with Life Score

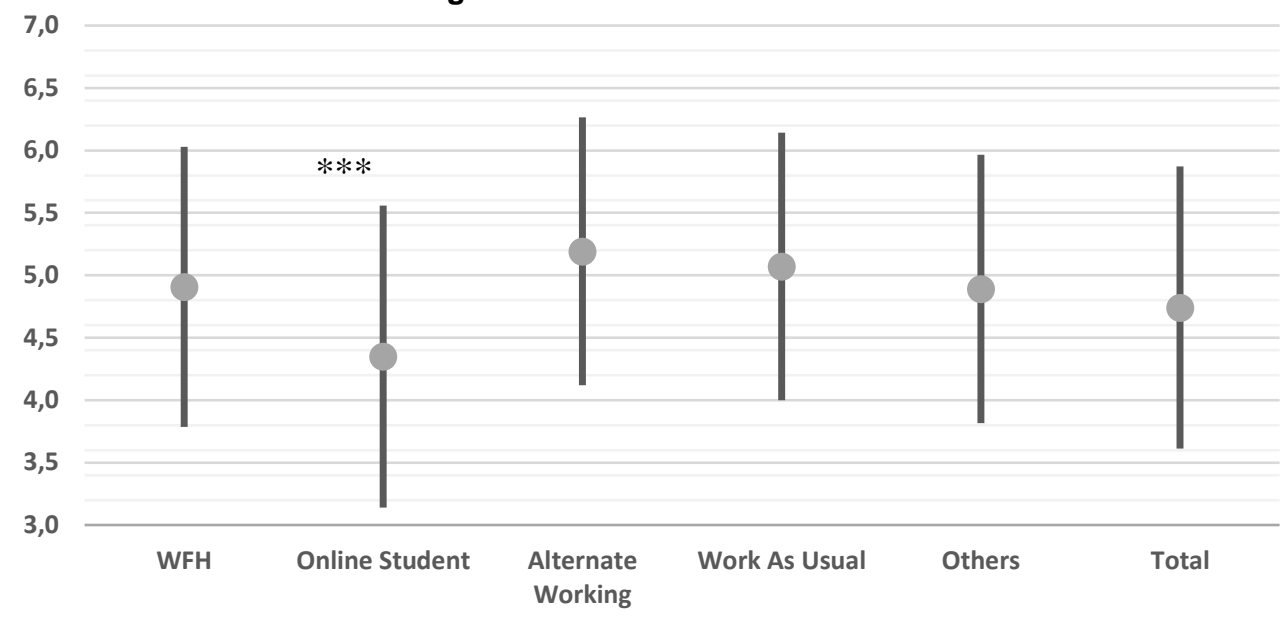

*** p-value $<0.05$

Figure 8. Deterioration of Satisfaction with Life

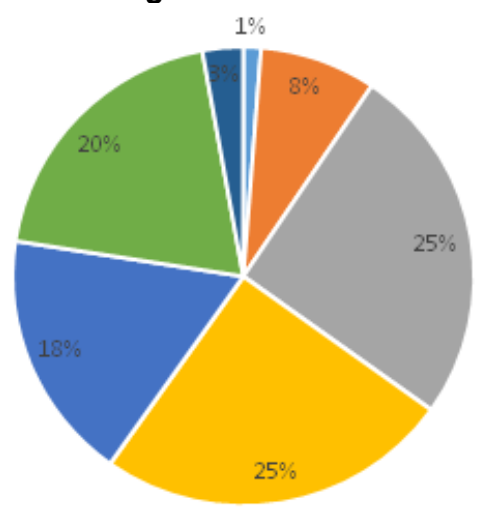

$$
\begin{aligned}
& \text { - Very deteriorated } \\
& \text { - Deteriorated } \\
& \text { - Slightly deteriorated } \\
& \text { = No Change } \\
& \text { - Slightly better } \\
& \text { - Better } \\
& \text { - Much better }
\end{aligned}
$$

Figure 9. Happiness and Satisfaction with Life Score compared to normal condition

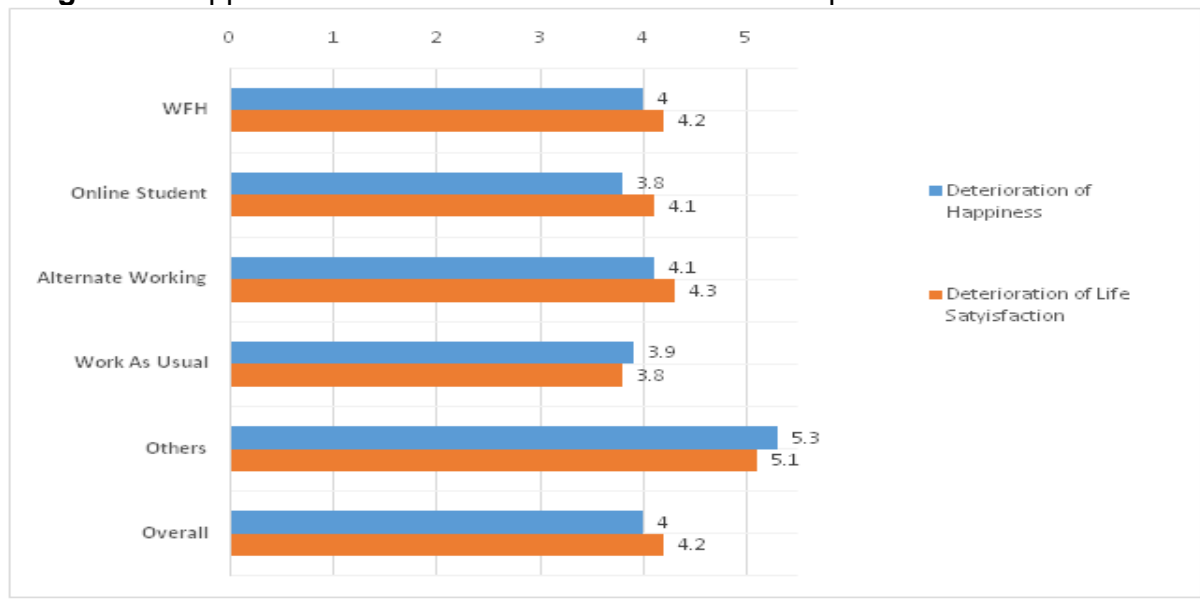

\section{Discussion}

On March $2^{\text {nd }}, 2020$, the government announced the first 2 cases of COVID-19 in Indonesia. Afterward, the number of cases has become escalating. Social distancing measures were implemented soon afterward. Schools were shifted to online method. Government institutions and private sectors implemented work from home and alternate working arrangements. Yet, some businesses still worked as usual with workspace arrangement. In Greater Jakarta, more than 20 million people got affected by mobility restriction. 
This study showed that during mobility restriction, people were only slightly happy. All groups showed no significant differences, except for students who had the lowest rate, and it was significant compared to the total respondents' rate. This study also showed that $41 \%$ of respondents claimed that their happiness was somehow deteriorated. In terms of satisfaction with life, total respondents also rated themselves only slightly satisfied. There were no significant differences in rate across all groups, except for students who had the lowest rate. The difference was significant compared to the total respondents' rate. This study also showed that $34 \%$ of respondents claimed that their satisfaction with life was somehow deteriorated.

Mobility restriction has caused conditions that affect people's happiness and satisfaction with life. The first condition is the limitation of physical activities. The mobility restriction has limited people in doing physical activities. Prohibition of people gathering has limited people in doing activities such as going to the gym, walking and jogging during car free day in the weekends, and going to shopping mall. Studies from (Tamminen et al., 2020) and (García-Hermoso et al., 2020) show that the limitation of physical activities has a significant negative impact on human wellbeing. The limitation of physical activities has also resulted in a lack of outdoor activities. Being outdoor increases people's wellbeing, does it show that the limitation of physical activities has a significant negative impact on human wellbeing? (MacKerron \& Mourato, 2013) suggest that being outdoor increases wellbeing with direct biophilia pathways or indirect effect through physical activities and social interaction.

The second condition caused by the COVID-19 outbreak is uncertainty. People do not know when this pandemic will end or when they can get back to normal life. They are also aware of the economic impact of this restriction, yet, they do not know how far this will affect their jobs. The impact of uncertainty to wellbeing is also confirmed by Murakami. After Fukushima disaster, people did not know whether to return home or not having a wellbeing reduction. Moreover, security is one of four psychological needs to be fulfilled in wellbeing.

Research reveals that people wellbeing will be met if four psychological needs are fulfilled. Being connected to others is one of these four psychological needs (Linley \& Joseph, 2004). Besides, Indonesian is known to be one with the highest sociability score $(0,79)$. That means, on average, Indonesian spends time every week with friends from social circles (Lussier, 2016). Indonesian often meets with friends, colleagues, and other community members. They meet on various occasions such as small reunions, friend 'arisan', family 'arisan', and religion group small gathering. The mobility restriction prohibits them from doing so. Some of those activities, now, are replaced with hanging out in zoom meeting, which is still less satisfactory. With high sociability characteristics, being restricted at home makes happiness and satisfaction deteriorated.

The group most affected by this mobility restriction was students. Another study by similar authors on e-learning during the COVID-19 outbreak has shown that what students do not like most about this mobility restriction is the lack of interaction with friends. The university students are mostly from the youngest generation, or Generation Z. This generation, even though, is known to be tech-savvy and hyper connected to the internet, they are also sociable (Dwidienawati \& Gandasari, 2018). Another study on WFH from similar authors reveals that one of the most unsatisfied people during WFH is family with children above 15 years old. People who do not have children at home or have children under 15 years old claim that they are rather satisfied with WFH. Children above 15 years old have their own needs to socialize with friends; therefore, being confined at home makes them feel unhappy and unsatisfied with life.

Wellbeing is known to link with health (Fancourt \& Steptoe, 2020; Lawrence et al., 2015; Tamminen et al., 2020). The deterioration of wellbeing might give an impact on people's general health. The result of the study showed that students should be one of the groups to get a priority for support to help them cope with the condition. 


\section{Conclusion}

Starting at the end of 2019, Coronavirus (COVID-19) has spread rapidly worldwide and become a pandemic, This large-scale pandemic outbreak is not only affecting human's health, but it is also affecting other aspects of human life. It is affecting day-to-day life significantly. In Jakarta and its surrounding cities, more than 20 million people get affected by mobility restriction. This mobility restriction might imply on health and wellbeing.

This study showed that in mobility restriction, the happiness level was only slightly happy, and the level of satisfaction was only slightly satisfied. Forty-one percent felt that their happiness was deteriorated during mobility restriction. Furthermore, thirty-four percent felt their satisfaction was deteriorated. The most impacted group in their scale of wellbeing was students. Their happiness and satisfaction were lower significantly compared to the total group score of happiness and satisfaction.

Wellbeing is known to link with health. The deterioration of wellbeing might give an impact on people's general health. This study gives a contribution to the literature of wellbeing, especially the impact of major life events on wellbeing. The finding of this study can give insight for policymakers in implementing restrictive measures. The result of this study gives an insight about which groups to get a priority for support to help them cope with the condition.

The limitation of this study is that it does not cover the elderly population which might get the worst impact than any other groups. This study was not designed as a mixed-method to dig further about the situation. Further studies to understand people's condition and reasoning will be beneficial. The respondents of the study were also mostly from Jakarta and its surrounding cities; therefore, it might not be generalized to the Indonesian population.

\section{References}

1. Conceição, P., \& Bandura, R. (2008). Measuring Subjective Wellbeing: A Summary Review of the Literature.

2. Diener, E., Emmons, R. A., Larsen, R. J., \& Griffin, S. (1985). The Satisfaction with Life Scale. Journal of Personality Assessment, 49, 71-75.

3. Dwidienawati, D., \& Gandasari, D. (2018). Understanding Indonesia's generation Z. International Journal of Engineering and Technology(UAE), 7(3). https://doi.org/10.14419/ijet.v7i3.25.17556

4. Fancourt, D., \& Steptoe, A. (2020). The longitudinal relationship between changes in wellbeing and inflammatory markers: Are associations independent of depression? Brain, Behavior, and Immunity, 83, 146-152. https://doi.org/10.1016/j.bbi.2019.10.004

5. Fisher, D., \& Wilder-Smith, A. (2020). The global community needs to swiftly ramp up the response to contain COVID-19. The Lancet, 395(10230), 1109-1110. https://doi.org/10.1016/S01406736(20)30679-6

6. García-Hermoso, A., Hormazábal-Aguayo, I., Fernández-Vergara, O., Olivares, P. R., \& OriolGranado, X. (2020). Physical activity, screen time and subjective well-being among children. International Journal of Clinical and Health Psychology. https://doi.org/10.1016/j.ijchp.2020.03.001

7. Huang, R. H., Liu, D. J., Tlili, A., Yang, J. F., \& Wang, H. H. (2020). Handbook on Facilitating Flexible Learning During Educational Disruption: The Chinese Experience in Maintaining Undisrupted Learning in COVID-19 Outbreak Please cite the work as follows : Smart Learning Institute of Beijing Normal University., (March).

8. Jongbloed, J., \& Andres, L. (2015). Elucidating the constructs happiness and wellbeing: A mixedmethods approach. International Journal of Wellbeing, 5(3), 1-20. https://doi.org/10.5502/ijw.v5i3.1

9. Lawrence, E. M., Rogers, R. G., \& Wadsworth, T. (2015). Happiness and longevity in the United States. Social Science and Medicine, 145, 115-119. https://doi.org/10.1016/j.socscimed.2015.09.020 
10.Linley, P. A., \& Joseph, S. (2004). Positive Psychology in Practice. John Wiley \& Sons.

11.Lussier, D. N. (2016). Contraining Elites in Russia and Indonesia. Cambridge University Press.

12.MacKerron, G., \& Mourato, S. (2013). Happiness is greater in natural environments. Global Environmental Change, 23(5), 992-1000. https://doi.org/10.1016/j.gloenvcha.2013.03.010

13.Mathews, G. (2012). Happiness, culture, and context. International Journal of Wellbeing, 2, 299312. https://doi.org/10.5502/ijw.v2.i4.2

14. Michalos, A. C. (2008). Education, happiness and wellbeing. Social Indicators Research, 87(3), 347366. https://doi.org/10.1007/s11205-007-9144-0

15.Orth, P., Schnappinger, D., Sum, P.-E., Ellestad, G. A., Hillen, W., Saenger, W., \& Hinrichs, W. (1999). Subjective Happiness Scale. Journal of Molecular Biology, 285, 455-461.

16.Peeri, N. C., Shrestha, N., Rahman, M. S., Zaki, R., Tan, Z., Bibi, S., ... Haque, U. (2020). The SARS, MERS and novel coronavirus (COVID-19) epidemics, the newest and biggest global health threats: what lessons have we learned? International Journal of Epidemiology, 19-21. https://doi.org/10.1093/ije/dyaa033

17.Tal, A., \& Kerret, D. (2020). Positive Psychology as a Strategy for Promoting Sustainable Population Policies. Heylon, 6(March), e03696. https://doi.org/10.1016/j.heliyon.2020.e03696

18.Tamminen, N., Reinikainen, J., Appelqvist-Schmidlechner, K., Borodulin, K., Mäki-Opas, T., \& Solin, P. (2020). Associations of physical activity with positive mental health: A population-based study. Mental Health and Physical Activity, 100319. https://doi.org/10.1016/j.mhpa.2020.100319

19.VanderWeele, T. J., Trudel-Fitzgerald, C., Allin, P., Farrelly, C., Fletcher, G., Frederick, D. E., ... Kubzansky, L. D. (2020). Current recommendations on the selection of measures for well-being. Preventive Medicine, 133(December 2019), 0-5. https://doi.org/10.1016/j.ypmed.2020.106004 